\title{
Association of the UCP-1 single nucleotide polymorphism A-3826G with the dampness-phlegm pattern among Korean stroke patients
}

Ji Hye Lim, Mi Mi Ko, Tae-Woong Moon, Min Ho Cha ${ }^{*}$ and Myeong Soo Lee

\begin{abstract}
Background: Patients with stroke have various syndromes and symptoms. Through pattern identification (PI), traditional Korean medicine (TKM) classifies the several syndromes and symptoms of stroke patients into five categories: Fire-heat (FH), Dampness-phlegm (DP), Yin-deficiency (YD), Qi-deficiency (QD) and Blood-stasis (BS). DP has been associated with obesity and hyperlipidemia. Uncoupling protein-1 (UCP-1), which plays a major role in thermogenesis and energy expenditure can increase the risk of obesity and can be related metabolic disorders. In this study, we elucidated the association of three polymorphisms located in the UCP-1 promoter and coding region with DP among Korean stroke patients.
\end{abstract}

Methods: 1,593 patients with cerebral infarction (583/DP, 1,010/non-DP) and 587 normal subjects were enrolled. The genotypes A-3826G, G-1766A and Ala64Thr (G+1068A) for each subject were determined by polymerase chain reaction with TaqMan probes and five percent of subjects were re-genotyped by sequencing method to confirm the accuracy of genotyping. The results were analyzed using a multiple logistic regression model to evaluate the genetic associations: the UCP-1polymorphisms of normal versus those of DP subjects and those of normal versus those of non-DP subjects.

Results: A significantly higher percentage of subjects in the DP group possessed the A-3826G G allele than the A allele $(O R=1.508, p=0.006)$. Furthermore, the number of subjects with the $G G$ type of $A-1766 G$ was significantly lower in the non-DP group than the normal group in the recessive model $(\mathrm{OR}=0.606, \mathrm{p}=0.042)$. In addition, an analysis of the relationship among 2 SNPs of UCP-1 and lipid serum concentration showed that the serum level of HDL cholesterol was significantly higher in subjects with the $\mathrm{A}-3826 \mathrm{G} \mathrm{G}$ allele in the normal group $(p=0.032)$. Serum triglyceride and $\mathrm{HDL}$ cholesterol were also associated with the A-1766G variant in the recessive model $(p=0.002, p=0.046)$.

Conclusions: These results suggest that that the A-3826G and A-1766G UCP-1 polymorphisms, which are related to obesity, might be candidate genetic markers for the DP pattern in the TKM diagnosis system.

Keywords: UCP-1, Polymorphism, Dampness-phlegm, A-3826G, A-1766G, Ala64Thr, Triglyceride

\footnotetext{
* Correspondence: mhchamin@kiom.re.kr

Medical Research Division, Korea Institute of Oriental Medicine, 1672

Yuseongdae-ro, Yuseong-gu, Daejeon 305-811, Republic of Korea
} 


\section{Background}

Uncoupling protein-1 (UCP-1) is a mitochondrial transporter that is present in the mitochondrial inner membrane, and it functions in ATP synthesis by dissipating oxidative energy from brown adipose tissue (BAT) [1,2]. The metabolic activities of BAT are related to the gene quantity of UCP-1 and the extent of stimulation of the sympathetic nervous system (SNS). Thus, polymorphism of the UCP-1 gene could have an adverse effect on energy homeostasis because of reduced mRNA expression [3].

UCP-1 plays important roles in energy homeostasis, and UCP-1 gene polymorphisms have been implicated in the pathogenesis of obesity and related metabolic disorders, including lipid disorders [3,4]. An A-3826G polymorphism within the promoter region of the UCP-1 gene is a candidate gene polymorphic site related to these disorders. The G allele of A-3826G was reported to be associated with higher body fat gain, increased BMI, and reduced postprandial thermogenesis by Nagai et al. and Oppert et al. [4,5] and also known to be related with resistance against diet-induced weight loss, reduced resting energy expenditure (REE) in young women, reinforcing the metabolic action of BAT and its effect on resting energy balance in adults [6]. The A1766G, which was found from Korean women, was also related with body fat mass and abdominal fat, and haplotype (GAG) constructed by A-3826G, A-1766G and Ala64Thr was shown to be associated with less reduction of waist-hip ratio (WHR) and body fat mass than in non-carriers among Korea women [5-7]. The Ala64Thr $(\mathrm{G}+1068 \mathrm{~A})$ is also known to be associated with increased WHR among Caucasians as well as lower fat content and WHR [8].

Traditional Korean medicine (TKM) is built on a medical foundation of comprehensive, integrated and holistic approaches. Pattern Identification (PI) in TKM is a unique diagnostic system that uses a comprehensive analysis on symptoms and signs [9], and is being categorized stroke into five PI: Fire-heat (FH), Qi-deficiency (QD), Dampness-phlegm (DP), Yin-deficiency (YD), and Blood-stasis (BS) [10-12]. Among these patterns, the DP pattern occurs by the prevention of Qi-blood circulation in the body, resulting in a pathological product due to various mechanisms [12]. Subjects with the DP tend to be obese and to have dyslipidemia, which is one of the causes of coronary disease $[13,14]$.

Recently, TKM research reported a relationship between single nucleotide polymorphisms (SNP) in the Paraoxonase 1 (PON1) or Neuropeptide Y (NPY) and DP pattern $[15,16]$. The C-2033T and L55M polymorphisms of PON1 were related with low antioxidant capacity and serum lipid levels with obese subjects in the DP group [15]. NPY, which is widely expressed in central and peripheral nervous systems, the $\mathrm{T}$ allele of C-399T has a negative association with DP pattern by decreased levels of serum cholesterol, which were significantly higher in DP group [16]. In this study, we investigated the genetic distribution of the 3 SNPs of UCP-1 among Korean stroke patients with cerebral infarction (CI) DP or non-DP group and compared with normal group.

\section{Methods}

\section{Study subjects}

A total of 2180 Korean subjects including 587 controls without any sign of stroke and $1593 \mathrm{CI}$ patients were enrolled in this study. In order to minimize the regional bias, the subjects were recruited from 10 Oriental Medical Hospitals from 2006 to 2010, including from KyungHee Oriental Medical Hospital (Houeugi, Koduk in Seoul), Dae-Jeon University Oriental Medical Hospital, Wonk-Kang Oriental Medical Hospital (Jeonju, Iksan), Dong-Guk Oriental Medical Hospital (Ilsan), KyungWon Oriental Medical Hospital (Seoul), Dong-Sin Oriental Medical Hospital (Kwangju, Sunchon), and Sang-Ji Oriental Medical Hospital. The classification on 583 DP and 1,010 non-DP group (FH, QD, YD and BS) was performed by two TKM doctors using the Standard Pattern Identification for Stroke (K-SPI-Stroke) [17]. Patients participated in this study were diagnosed as cerebral infarction by computed tomography or magnetic resonance imaging. CI subtypes included large artery atherosclerosis (LAA), cardioembolism (CE), small vessel occlusion (SVO), stroke of other determined etiology (SOE) and stroke of undetermined etiology (SUE) subtype according to the Trial of ORG 10172 in Acute Stroke Treatment (TOAST) classification. Individuals with signs of stroke were excluded from normal groups. Subjects with infectious disease and liver diseases were also excluded. This study was approved by the Institutional Review Boards of the Korean institute of Oriental Medicine and by each of the Oriental Medical Hospitals.

\section{Laboratory analysis}

Anthropometric parameters of each subject were obtained with a questionnaire described by Kang et al. [14]. The level of serum parameters including fasting blood sugar (FBS), total cholesterol (TC), triglyceride (TG) and high density lipoprotein (HDL-C) were determined by automated biochemical analyzer (Olympus AU400,Japan).

\section{Preparation of genomic DNA and identification of SNPs}

Blood from each subject was collected after obtaining informed consent, and genomic DNA from each blood sample was isolated using a GeneAll genomic isolation kit (GeneAll, Seoul, Korea) according to the manufacturer's instructions. The three SNPs of UCP-1 were genotyped using the TaqMan method with polymerase 
chain reaction (PCR) primers and TaqMan probes designed by ABI, Inc. (Applied Biosystems, Inc., USA). Primer information for each SNP is shown in Additional file 1: Table S1. In addition, samples for $5 \%$ of the participants were validated by sequencing to confirm the genotyping accuracy. The genotyping error rate was $0.3 \%$ according to the direct sequencing of PCR products (data not shown). The kappa value of each SNP ranged from 0.93 to 100 , which indicates good accuracy. The Hardy-Weinberg equilibrium (HWE) was calculated using $X^{2}$ tests, and a linkage disequilibrium (LD) analysis was performed to examine the relationship between each SNP and was constructed by HapAnalyzer software [18].

\section{Statistical analyses}

Data were statistically analyzed with SAS software, version 9.1.3 (SAS Institute, Inc., NC). Differences in continuous variables were determined by Student's $t$-test or Wilcoxon rank-sum test after confirming normality by a Kolmogorov-Smimov test. Categorical variables were compared with a Chi-squared test or Fisher's exact test. Estimation of the association of SNPs with DP was performed by multiple logistic regression, which was adjusted for sex, age, smoking status and drinking status, as well as odds ratios (ORs), with 95\% confidence intervals $(95 \% \mathrm{CI})$. The effect of the A-3826G and A1766G polymorphisms on serum lipid and sugar in the normal group was evaluated by a general linear model after adjusting for sex, age, smoking status and drinking status. Statistical significance was set at $\mathrm{p}<0.05$.

\section{Results}

The demographic and clinical characteristics of CI patients classified as DP group or Non-DP group and normal subjects are summarized in Table 1 . The results showed that body characteristics (weight, waist, and WHR) values in DP group were significantly higher than those in normal group $(\mathrm{p}<0.0001)$. Additionally, serum lipid parameter (total cholesterol and triglyceride) levels were higher in the DP group than those in non-DP group. General characteristics of subjects in each pattern of Non-DP group are shown in Additional file 2: Table S2. The locations of 3 SNPs within the UCP-1 gene are shown in Figure 1(A), and their characteristics are listed in Table 2. Two of these SNPs are located in the UCP-1 promoter region, and the other SNP is located in exon 2. All of the studied SNPs satisfied the HardyWeinberg equilibrium ( $p>0.05$ ) according to the International HapMap Project [17]. The LD coefficients between the 3 SNPs are shown in Figure 1(B). The value of $r^{2}$ was 0.008-0.284, which means that the three SNPs were not linked. These results are consistent with

Table 1 General characteristics of the study subjects

\begin{tabular}{|c|c|c|c|c|c|}
\hline Characteristic & Normal (N) & Non-dampness-phlegm (N) & Sig. ${ }^{a}$ & Dampness-phlegm (N) & Sig. ${ }^{b}$ \\
\hline $\operatorname{Sex}(M / F)$ & $273 / 314$ & $619 / 523$ & 0.0024 & $314 / 331$ & 0.4453 \\
\hline Age (year) & $64(58,69)$ & $70(60,76)$ & $<0.0001$ & $69(61,75)$ & $<0.0001$ \\
\hline $\begin{array}{l}\text { TOAST } \\
\text { (LAA/CE/SVO/SOE/SUE) }\end{array}$ & - & 248/77/617/17/48 & & $128 / 31 / 386 / 26$ & \\
\hline Weight (kg) & $62.0(56.0,69.0)$ & $60.0(53.0,68.0)$ & 0.0001 & $63.0(56.0,70.0)$ & 0.0461 \\
\hline $\mathrm{BMI}\left(\mathrm{kg} / \mathrm{m}^{2}\right)$ & $24.17(22.65,26.02)$ & $23.28(21.29,25.39)$ & $<0.0001$ & $24.6(22.5,26.7)$ & 0.0588 \\
\hline Waist (cm) & $85.0(79.0,90.0)$ & $86.0(80.0,92.0)$ & 0.0032 & 89.0(82.0, 95.0) & $<0.0001$ \\
\hline Hip (cm) & $96.0(92.0,100.0)$ & $93.0(87.5,98.0)$ & $<0.0001$ & $95.0(89.0,99.0)$ & 0.0002 \\
\hline WHR & $0.88(0.85,0.91)$ & $0.93(0.89,0.97)$ & $<0.0001$ & $0.94(0.90,0.97)$ & $<0.0001$ \\
\hline Smoking $(\mathrm{Y} / \mathrm{N})$ & $56 / 531$ & $292 / 850$ & $<0.0001$ & $153 / 491$ & $<0.0001$ \\
\hline Drinking $(\mathrm{Y} / \mathrm{N})$ & 195/392 & $416 / 726$ & $<0.0001$ & 196/447 & 0.0206 \\
\hline $\mathrm{GOT}(\mathrm{U} / \mathrm{ml})$ & $23.0(18.0,29.0)$ & $22.1(18.0,29.0)$ & 0.0001 & $23.0(18.0,28.1)$ & 0.0005 \\
\hline GPT (U/ml) & $21.0(16.0,30.0)$ & $19.0(14.0,29.0)$ & $<0.0001$ & $19.0(14.0,28.0)$ & $<0.0001$ \\
\hline T-Cholesterol (mg/dL) & $199.0(175.0,226.0)$ & $180.0(152.0,210.0)$ & $<0.0001$ & 189.0(160.0, 219.0) & $<0.0001$ \\
\hline Trig $(\mathrm{mg} / \mathrm{dL})$ & $131.0(91.0,182.0)$ & $127.0(90.0,185.0)$ & 0.8524 & $132.0(94.0,195.0)$ & 0.1055 \\
\hline $\mathrm{HDL}(\mathrm{mg} / \mathrm{dL})$ & $51.0(43.2,59.9)$ & $42.0(35.0,50.0)$ & $<0.0001$ & $41.0(33.5,48.8)$ & $<0.0001$ \\
\hline $\mathrm{FBS}(\mathrm{mg} / \mathrm{dL})$ & $99.0(92.0,106.0)$ & $105.0(93.0,132.0)$ & $<0.0001$ & $107.0(94.0,128.0)$ & $<0.0001$ \\
\hline BUN & $14.5(12.0,17.6)$ & $14.0(11.5,18.0)$ & 0.3859 & $13.9(11.0,17.1)$ & 0.0031 \\
\hline $\mathrm{Cr}$ & $0.90(0.70,1.00)$ & $0.90(0.70,1.00)$ & 0.521 & $0.80(0.70,1.00)$ & 0.0002 \\
\hline
\end{tabular}

* Data were expressed as frequencies for categorical variables and as the mean \pm standard deviation for continuous variables.WHR: waist hip ratio. TOAST: trial of ORG 10172 in acute stroke treatment. LAA: large-artery atherosclerosis. CE: cardio embolism. SVO: small vessel occlusion. SOE: stroke of other etiology. SUE stroke of undetermined etiology. GOP: glutamate oxaloacetate transaminase. GPT: glutamate pyruvate transaminase. Trig: Triglyceride sig.a: $P$ value of normal versus non-dampness-phlegm using a Chi-squared test for categorical variables and the Wilcoxon two-sample test for continuous variables. sig.b: $P$ value of normal versus dampness-phlegm using a Chi-squared test for categorical variables and the Wilcoxon two-sample test for continuous variables. 


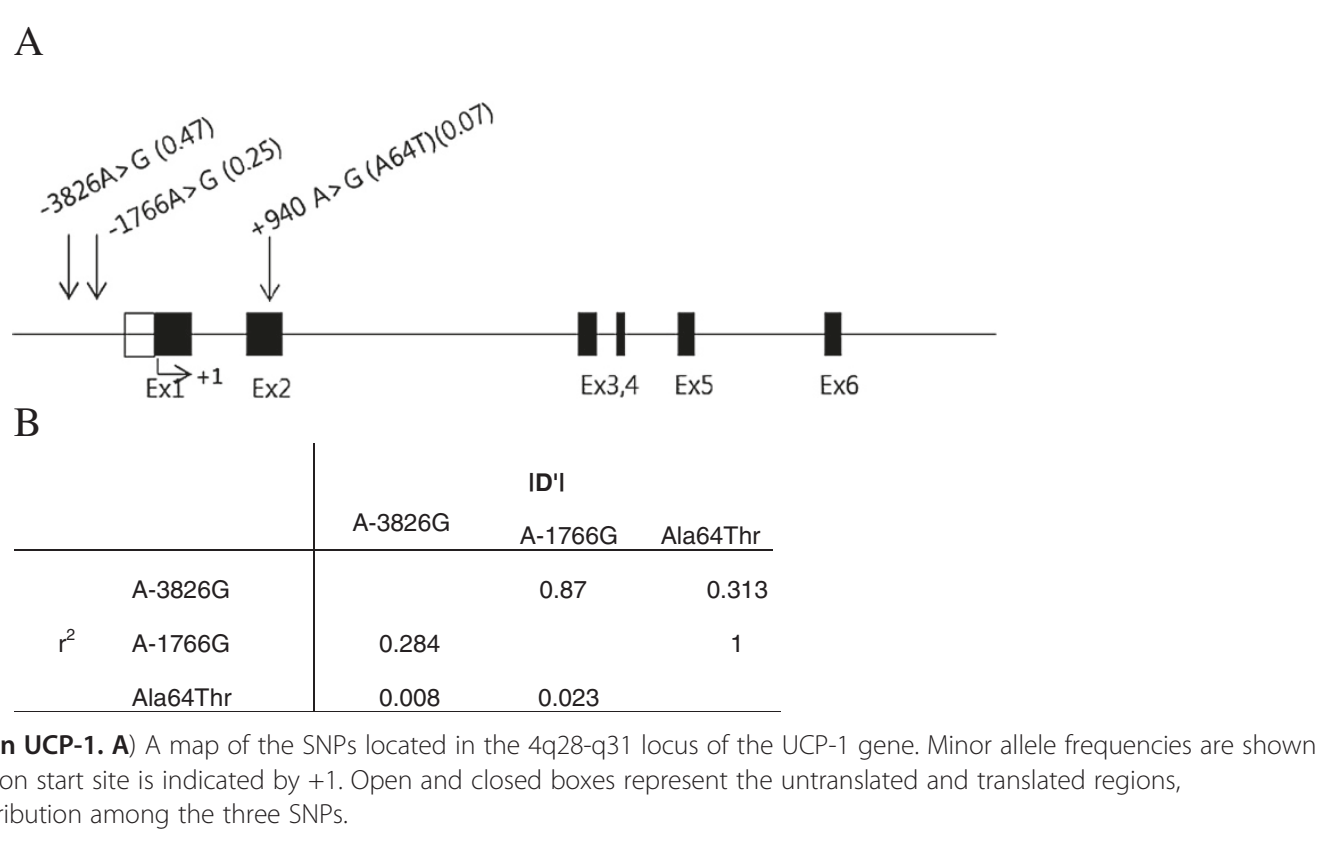

previous reports, and the SNP distribution in normal subjects was polymorphic and in accord with the HWE in Table 2. Table 3 shows the allele and genotype distribution of the three SNPs in the non-DP and DP groups compared with the normal groups. The percentage of subjects with the $G$ allele of A-3826G was significantly higher in the DP group than in the normal group in the dominant model $(77.76 \%$ in dampness-phlegm vs. $71.77 \%$ in normal, $\mathrm{OR}=1.508, \mathrm{p}=0.006$, power $=85.3 \%$ ). In other hand, G allele of A-1766G and A allele of Ala64Thr were previously revealed to be highly related to obesity showed little relation with obesity in this study of comparing the DP group with normal group. However, the $G$ allele frequency of A-1766G was significantly lower in the non-DP group than the normal group in the recessive model (4.77\% in non-dampness-phlegm vs. $5.10 \%$ in normal, $\mathrm{OR}=0.606, \mathrm{p}=0.0423$, power $=56.9 \%$ ).

To confirm which factor was affected by A-3826G or A-1766G, we compared serum lipid parameters according to genotype in normal subjects (Table 4). A-3826G was associated with serum HDL-C. The mean serum HDL-C of the subjects with the GA and GG type at the -3826 position of the UCP-1 gene was $52.74 \mathrm{mg} / \mathrm{dL}$ and $54.63 \mathrm{mg} / \mathrm{dL}$, respectively. These means were significantly higher than the mean serum HDL-C (50.92 $\mathrm{mg} / \mathrm{dL}$ ) of the subjects with the AA type in the dominant model $(\mathrm{p}=0.0317$, power $=50.3 \%)$. The level of serum triglycerides $(\mathrm{p}=0.0229$, power $=97.5 \%)$ and HDL-C $(\mathrm{p}=0.0465$, power $=39.3 \%)$ was associated in the recessive model. However, parameters on obesity and serum lipids were not significantly different between DP group and non-DP group (data not shown).

\section{Discussion}

A recent study published by Kim et al. explained that dampness-phlegm is an impediment to Qi, energy that circulates in channels called meridians and that causes various symptoms and signs when blocked or disrupted because of its high turbidity, heaviness, stickiness, and downward flowing properties $[12,19]$. In addition, DP was related to clinical indicators, such as overweight, pale tongue, and slippery pulse [12]. In TKM, DP has long been a suspected as a cause for obesity. Dong-euibo-gam, which are the most extensively read medical texts by TKM doctors and are praised as one of the

Table 2 Characteristics of SNPs identified by genomic sequencing of the promoter and exon of UCP-1 in the normal group

\begin{tabular}{|c|c|c|c|c|c|c|c|c|}
\hline \multirow[t]{2}{*}{ SNP } & \multirow[t]{2}{*}{ Rs No. } & \multirow[t]{2}{*}{ Position } & \multirow{2}{*}{$\begin{array}{l}\text { Nucleotide } \\
\text { change }\end{array}$} & \multicolumn{3}{|c|}{ Genotype distribution (N) } & \multirow{2}{*}{$\begin{array}{l}\text { Minor allele } \\
\text { frequency }\end{array}$} & \multirow[t]{2}{*}{ HWE $p$} \\
\hline & & & & $\mathrm{CC}$ & CR & $\mathbf{R R}$ & & \\
\hline$A-3826 G$ & rs1800592 & Promoter & $A>G$ & 126 & 291 & 164 & 0.4673 & 0.8845 \\
\hline$A-1766 G$ & rs3811791 & Promoter & $A>G$ & 335 & 201 & 43 & 0.2478 & 0.0974 \\
\hline Ala64Thr & rs45539933 & Exon2 & $A>G$ & 508 & 77 & 0 & 0.0658 & 0.0883 \\
\hline
\end{tabular}


Table 3 The genotype distribution of UCP-1 polymorphisms in the dampness-phlegm and non-dampness-phlegm groups compared with the normal group

\begin{tabular}{|c|c|c|c|c|c|c|c|c|c|}
\hline \multirow[t]{2}{*}{ Model } & \multirow[t]{2}{*}{ SNPs } & \multirow[t]{2}{*}{ Genotype } & \multirow[t]{2}{*}{ Normal } & \multirow{2}{*}{$\frac{\text { Non-dampness }}{\text { phlegm }}$} & \multirow[t]{2}{*}{ OR $[95 \% \mathrm{Cl}]$} & \multirow[t]{2}{*}{$p$} & Dampness & \multirow[t]{2}{*}{ OR $[95 \% \mathrm{Cl}]$} & \multirow[t]{2}{*}{$p$} \\
\hline & & & & & & & Phlegm & & \\
\hline \multirow[t]{6}{*}{ Allele } & A-3826G & A & $619(53.27)$ & $1,032(51.43)$ & 1.097 & 0.2586 & $575(49.57)$ & 1.205 & 0.0443 \\
\hline & & G & $543(46.73)$ & 978 (48.66) & $(0.934,1.290)$ & & $585(50.43)$ & $(1.005,1.444)$ & \\
\hline & $A-1766 G$ & $A$ & 871 (75.22) & $1512(75.6)$ & 0.968 & 0.7371 & 873 (75.91) & 0.98 & 0.8548 \\
\hline & & G & 287 (24.78) & $488(24.4)$ & $(0.802,1.169)$ & & $277(24.09)$ & $(0.793,1.212)$ & \\
\hline & Ala64Thr & A & 77 (6.58) & $130(6.45)$ & 0.984 & 0.9226 & 91 (7.84) & 0.879 & 0.468 \\
\hline & & G & $1,093(93.42)$ & $1,886(93.55)$ & $(0.710,1.364)$ & & $1,069(91.67)$ & $(0.621,1.245)$ & \\
\hline \multirow[t]{6}{*}{${ }^{\dagger}$ Do } & $A-3826 G$ & AA & $164(28.23)$ & $267(26.57)$ & 1.168 & 0.2319 & $129(22.24)$ & 1.508 & 0.0065 \\
\hline & & $A G+G G$ & 417 (71.77) & 738 (73.43) & $(0.906,1.506)$ & & $451(77.76)$ & $(1.122,2.028)$ & \\
\hline & $A-1766 G$ & $\mathrm{AA}$ & $335(57.86)$ & $563(56.3)$ & 1.066 & 0.5872 & $328(57.04)$ & 1.023 & 0.8644 \\
\hline & & $A G+G G$ & $244(42.14)$ & $437(43.7)$ & $(0.846,1.344)$ & & $247(42.96)$ & $(0.789,1.327)$ & \\
\hline & Ala64Thr & GG & $508(86.84)$ & $879(87.2)$ & 0.989 & 0.9489 & 492 (84.83) & 1.087 & 0.6157 \\
\hline & & $\mathrm{GA}+\mathrm{AA}$ & 77 (13.16) & $129(12.8)$ & $(0.704,1.389)$ & & $88(15.17)$ & $(0.762,1.583)$ & \\
\hline \multirow[t]{6}{*}{${ }^{\dagger} \mathrm{R}$} & A-3826G & $\mathrm{AA}+\mathrm{AG}$ & 455 (78.31) & 765 (76.12) & 1.093 & 0.5257 & 446 (76.90) & 1.092 & 0.5749 \\
\hline & & GG & 126 (21.69) & $240(23.38)$ & $(0.831,1.437)$ & & $134(23.10)$ & $(0.803,1.485)$ & \\
\hline & A-1766G & $A A+A G$ & $536(92.57)$ & $949(94.9)$ & 0.606 & 0.0423 & 545 (94.78) & 0.801 & 0.4183 \\
\hline & & GG & $43(7.43)$ & $51(5.1)$ & $(0.374,0.983)$ & & $30(5.22)$ & $(0.468,1.371)$ & \\
\hline & Ala64Thr & $\mathrm{GG}+\mathrm{GA}$ & $585(100)$ & $1,007(99.9)$ & ND & ND & 577 (99.48) & ND & ND \\
\hline & & $\mathrm{AA}$ & $0(0)$ & $1(0.1)$ & & & $3(0.52)$ & & \\
\hline
\end{tabular}

* The values indicate the frequency of subjects (\%). OR ( $95 \% \mathrm{Cl})$ and Siga, Sigb value were calculated using a binary logistical regression model adjusted for sex, age, smoking, and drinking with normal versus non-dampness-phlegm, normal versus dampness-phlegm . tDo and R denote dominant and recessive models, respectively. $\mathrm{Cl}$ : confidence interval. $P$-values with statistical significance were presented in bold $(<0.05)$.

most important medical texts in TKM [20], declared dampness-phlegm as a main factor of obesity, stating that overweight people have an abnormal biomechanical flow and that the Qi deficiency generates cold, cold generates dampness, and dampness generates phlegm, which finally leads to obesity [21]. Recently, there have been several scientific attempts to verify the relationship between DP and obesity. The study of the relationship of DP tongue diagnosis to hyperlipidemia in stroke suggests that serum lipid levels, such as total cholesterol, HDL cholesterol, and triglyceride, were higher in the DP group than those in the non-DP group [12]. In addition, Min et al. reported that TC, BMI and waist circumference were significantly increased in DP patients [22]. A case-control study of the relationship of DP and blood lipid levels revealed that DP was significantly correlated with increased LDL cholesterol and was an independent predictor of hyperlipoproteinemia [23]. However, few studies using a genetic analysis to prove the relationship between DP and obesity have been carried out up to now. An analysis on obesityrelated genotype can provide a significant insight to present scientific evidence including a number of clinical trials that show the relationship between DP and obesity. UCP-1 is a major obesity-related gene that regulates energy homeostasis inside body [24]. When exposed to

Table 4 Association analysis of serum biochemical parameters by genotype of UCP-1 among the normal group

\begin{tabular}{|c|c|c|c|c|c|c|c|c|c|c|}
\hline \multirow[t]{3}{*}{ Parameter } & \multicolumn{6}{|l|}{ Genotype } & \multicolumn{4}{|l|}{$P$} \\
\hline & \multicolumn{3}{|c|}{ A-3826G } & \multicolumn{3}{|l|}{ A-1766G } & \multicolumn{2}{|c|}{$A-3826 G$} & \multicolumn{2}{|c|}{ A-1766G } \\
\hline & $\overline{A A}$ & AG & GG & $\overline{\mathrm{AA}}$ & AG & GG & $\overline{\text { Do }}$ & $\mathbf{R}$ & Do & $\mathbf{R}$ \\
\hline$n$ & 164 & 291 & 125 & 335 & 200 & 43 & & & & \\
\hline BMI (kg/m2) & $24.44 \pm 2.76$ & $24.30 \pm 2.56$ & $24.59 \pm 3.01$ & $24.30 \pm 2.68$ & $24.49 \pm 2.81$ & $24.70 \pm 2.66$ & 0.9351 & 0.4065 & 0.3249 & 0.463 \\
\hline $\mathrm{TC}(\mathrm{mg} / \mathrm{dl})$ & $201.52 \pm 43.28$ & $204.15 \pm 37.74$ & $196.79 \pm 37.72$ & $202.46 \pm 40.18$ & $201.52 \pm 38.82$ & $196.98 \pm 38.69$ & 0.8485 & 0.0708 & 0.5684 & 0.3833 \\
\hline$\overline{\mathrm{TG}}(\mathrm{mg} / \mathrm{dL})$ & $151.66 \pm 89.69$ & $149.56 \pm 78.51$ & $137.61 \pm 78.32$ & $150.28 \pm 74.70$ & $147.42 \pm 84.47$ & $111.60 \pm 58.36$ & 0.4427 & 0.1699 & 0.2031 & 0.0028 \\
\hline HDL-cholesterol (mg/dl) & $50.92 \pm 12.41$ & $52.74 \pm 12.79$ & $54.63 \pm 14.26$ & $51.63 \pm 12.97$ & $53.37 \pm 12.89$ & $56.43 \pm 14.36$ & 0.032 & 0.0847 & 0.0379 & 0.0465 \\
\hline
\end{tabular}

The value indicates the number of subjects (mean \pm SD). The $\mathrm{p}$ value was calculated using a general linear model adjusted for sex, age, smoking, and drinking. Statistical significance was presented in bold $(<0.05)$. Do, and $\mathrm{R}$ denote dominant, and recessive models, respectively. 
coldness, the expression of UCP-1 is promoted by adaptive thermogenesis, that is, heat generation consuming $\mathrm{pH}$-gradient induced by oxidative phospholyation and by increased adrenergic stimulation, $\beta 3$-agonists, retinoids, thyroid hormone, PPAR $\gamma$ ligand and leptin $[25,26]$.

However, the inhibition of gene expression or gene activity caused by genetic deficiency of UCP-1 may result in imbalance on heat generation inside body, which changes in the oxidation of free fatty acids in the mitochondria can alter the blood levels of lipids through tissue cholesterol transport and ultimately lead to obesity. Therefore, this mechanism to control blood lipids may be affected by genetic polymorphisms such as A-3826G polymorphism of UCP-1 gene [27]. This was proved by a study that showed lowered activation of sympathetic nerve and declined expression of UCP-1 in BAT of obese rats and by another in vivo study that reported overexpression of UCP-1 reduced degree of obesity induced by high fat diet. This signifies the acceleration of energy consumption by the expression of UCP-1 is effective to the prevention and suppression of obesity $[28,29]$.

The A-3826G, A-1766G and Ala64Thr, polymorphisms of UCP-1 gene, were previously associated with weight loss, abdominal obesity and metabolic disorder, which are risk factors of stroke. In the current study, we examined that A-3826G SNP were significantly associated with DP among Korean stroke patients. The G allele frequency of A-3826G was significantly higher than the A allele in the DP group ( $\mathrm{p}=0.0247)$, and the number of subjects with the GG or GA genotype was larger than those with the AA type. A large distribution of $G$ allele revealed after the analysis on A-3826G polymorphism among the patients with DP is also found among the obese [30]. Considering DP acts as a causative factor of obesity in TKM, and UCP-1 is regulator of obesity, DP and UCP-1 seem to be highly associated each other. Investigating the genetic polymorphic distribution is meaningful to predict and diagnose obesity.

Oberkoflr et al. reported that UCP-1 mRNA levels in visceral fat were lower in obese subjects and that UCP-1 mRNA levels in fat tissue were regulated by the UCP-1 genotype $[31,32]$. This result may have been observed because the G allele carrier of A-3826G in UCP-1 regulated by the extent of obesity may have reduced expression, which causes less energy dissipation as heat.

This study has several limitations. The first limitation relates to the diagnostic standard for PI. The PI types were confirmed by two experts with sufficient clinical experiences. Nevertheless, their diagnoses did not match. PI still has limitations in consistency and reproducibility because of its high dependence on subjective diagnostic indicators. Second, although DP in TKM is generally considered as a major causative factor for obesity, DP is not the sole cause that induces obesity, and other pattern such as Fire-Heat has also potential to result in obesity [33]. Third, sample size was not enough to generalize the association between UCP-1 polymorphisms and DP. Especially, the number of subjects in normal group was smaller than that of the patients group. Thus, a further study to confirm the association will be needed.

We already reported that polymorphisms of the PON1 and NPY genes, which were associated with stroke and obesity, were related to DP among Korean stroke patients. The results of this study replicate the relationship that other studies have found between genetic polymorphism and PI, and the A-3826G SNP of the UCP-1 gene might be a predictive genetic marker for DP pattern.

\section{Conclusions}

We showed an association of UCP1 polymorphisms with DP in Korean stroke patients. A-3826G and A-1766G UCP-1 polymorphisms, which are related to obesity, might be candidate genetic markers for DP pattern in the TKM diagnosis system.

\section{Additional files}

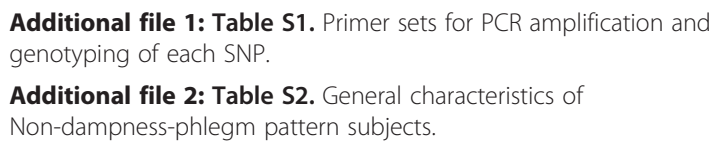

\section{Competing interests}

The authors declare that they have no competing interests.

\section{Authors' contributions}

JHL: performance of experiments, data analysis, writing manuscript. MMK: data analysis (statistics). TWM and MSL: design and coordination and helped to draft the manuscript. MHC: experimental design, performance of experiments, writing manuscript. All of the authors read and approved the final manuscript.

\section{Acknowledgements}

This research was supported by a grant from the Korea Institute of Oriental Medicine (K12130).

Received: 13 June 2012 Accepted: 26 September 2012

Published: 9 October 2012

\section{References}

1. Ricquier D, Bouillaud F, AM CD, Miroux B, Mozo J, MC AG, Rousset S: The biology of mitochondrial uncoupling proteins. Diabetes 2004, 53:130-135.

2. Collins S, Cao W, Daniel KW, Tonya MD, Medvedev AV, Onuma H, Surwit R: Uncoupling proteins, and energy expenditure. Exp Biol Med 2001, 226:982-990.

3. Park MJ: Recent Advances in Regulating Energy Homeostasis and Obesity. Korean Journal of Pediatrics 2005, 2:126-137.

4. Nagai N, Sakane N, Kotani K, Hamada T, Tsuzaki K: Uncoupling protein 1 gene $-3826 \mathrm{~A} / \mathrm{G}$ polymorphism is associated with weight loss on a short term, controlled-energy diet in young women. Nutr Res 2011, 31:255-261.

5. Oppert JM, Vohl MC, Chagnon M, Dionne FT, Doulcier AM, Ricquier D, Perusse $\mathrm{L}$, Bouchard $\mathrm{C}$ : DNA polymorphism in the uncoupling protein 
(UCP) gene and human body fat. Int J Obes Relat Metab Disord 1994, 18:526-531.

6. Shin HD, Kim KS, Cha MH, Yoon YS: The effect of UCP-1 polymorphisms on obesity phenotypes among Korean female subjects. Biochem Biophys Res Commun 2005, 335:624-630.

7. Kim KS, Cho DY, Kim YJ, Choi SM, Kim JY, Shin SU, Yoon YS: The finding of new genetic polymorphism of UCP-1 A-1766G and its effects on body fat accumulation. Biocmimica et Biophysica Acta 2005, 1741:149-155.

8. Herrmann SM, Wang JG, Staessen JA, Kertmen E, Schmidt-Petersen K, Zidek W, Paul M, Brand E: Uncoupling protein 1 and 3 polymorphisms are associated with waist-to-hip ratio. J Mol Med 2003, 81:327-332.

9. Park TY, Lee JA, Cha MH, Kang BK, Moon TW, Choi TY, Ko MM, Choi JA, Lim $\mathrm{JH}$, Jeong HY, Lee MS: The Fundamental Study for the Standardization and Objectification of Pattern Identification in Traditional Korean Medicine for Stroke (SOPI-Stroke): An overview of phase I. European Journal of Integrative Medicine 2012, :-133-e139.

10. Lee JA, Lee JS, Kang BK, Ko MM, Moon TW, Cho KH, et al: Report on the Korean Standard Pattern Identifications for Stroke-III. Korean Journal of Oriental Internal Medicine 2011, 32:232-242.

11. Go HY, Kim YK, Kang BK, et al: Report on the Korean standard differentiation of the symptoms and signs for the stroke-2. Korean Journal of Oriental Physiology\& Pathology 2006, 20:1789-1791.

12. Kim HJ, Bae HS, Park SU, Moon SK, Park JM, Jung WS: Clinical approach to the standardization of oriental medical diagnostic pattern identification in stroke patients. Evidence based Complementary and Alternative Medicine 2011, :7. Article ID 768492.

13. Jung WW, Lee WC: The Literature on "Dam-eum" resulted on stroke. Dongguk J. the institute of oriental medicine 1999, 8:133-144.

14. Kang JS, Kim DH, Shin HS, Cho CH, Lee JH, Kang BK, An JJ, Jo HK, et al: The study on relationship of Dampness-phlegm tongue diagnosis to hyperlipidimia in stroke patients. J of KIOM 2009, 13:24-33.

15. Lim JH, Ko MM, Lee JS, Bang OS, Cha MH: Genetic association of SNPs located at PON1 gene with dampness and phlegm pattern identification among Korea stroke patients. KJ. Oriental Med 2010, 31:752-762.

16. Ko MM, Kang BK, Lim JH, Lee MS, Cha MH: Genetic Association of NPY Gene Polymorphisms with Dampness-Phlegm Pattern in Korean Stroke Patients. Evid Based Complement Alternat Med 2012, 7. Article ID 109796.

17. Kang BK, Park TY, Moon TW, Lee JA, Ko MM, Choi JA, Lee MS: Reliability and validity of a Pattern Identification Questionnaira for Koran stroke patients. BMC Complement Altern Med 2012, 12:55.

18. Jung HY, Park JS, Park YJ, Kim YJ, Kim K, Koh IS: Hapanlyzer; Minimum Haplotype Analysis System for Association Studies. Genomics \& Informatics 2004, 2:107-109.

19. Wood DL, Wood JL: Acupuncture Handbook. Health Science Press 1964, 4:133.

20. Heo J: Dongeuibogam. Dongeuibogam Press 2005, 920.

21. Heo J, Park CK: A study on Heo Joon's life and examining about Dongeuibogam. K.H. Univ. O. Med. J 1986, 9:301-318.

22. Min IK, Kim CH, Hwang JW, et al: The relation of Dampness-Phlegm and metabolic syndrome in acute stroke patients. Journal of Korean Oriental Medicine 2009, 30:109-119.

23. Kim MJ, Kang BK, An JJ, Yoo HR, Kim YS, Seol IC: Case-control study on relationship of dampness-phlegm to blood lipid level in stroke patients. K.J. Oriental Physiology \& Pathology 2006, 23:1470-1479.

24. Cho HJ, Kim WS, Park SY, Kim JB: PPARs and UCPs: Two major regulator in energy homeostasis. Biochemistry News 2002, 22:256-265.

25. Prusiner SB, Cannon B, Ching TM, Lindberg O: Oxidative metabolism in cell isolated from brow adipose tissue. 2. Catecholamine regulated respiratory control. Eur J Biochem 1968, 7:51-57.

26. Bukowiecki $\sqcup$, Follea N, Lupien J, Paradis A: Metabolic relationships between lipolysis and respiration in rat brown adipocytes. The role of long chain fatty acids as regulators of mitochondrial respiration and feedback inhibitors of lipolysis. J Biol Chem 1981, 256:12840-12848.

27. Kazuhiko K, Shinji F, Kokoro T, Yoshiko S, Narumi N, Toshiyuki Y, Naoki S: The Association Between the Uncoupling Protein-1 Gene A-3826G Polymorphism and High-density Lipoprotein Cholesterol in A General Japanese Population: A Consideration of the Obesity Status. J Clin Med Res 2011, 3:319-324.

28. Himms-Hagen J: Brown adipose tissue thermogenesis and obesity. Prog Lipid Res 1989, 28:67-115.

29. Collins $S$, et al: Role of leptin in fat regulation. Nature 1996, 380:677.
30. Dhall M, Chaturvedi MM, Rai U, Kapoor S: Sex-dependent effects of the UCP1 $-3826 \mathrm{~A} / \mathrm{G}$ polymorphism on obesity and blood pressure. Ethn Dis 2012, 22:181-184.

31. Oberkofler H, Dallinger G, Liu YM, Hell E, Krempler F, Patsch W: uncoupling protein gene: quantification of expression levels in adipose tissue of obese and non-obese human. J Lipid Res 1997, 38:2125-2133.

32. Esterbauer H, Oberkofler H, Liu YM, Breban D, Hell E, Krempler F, Patsch W: Uncoupling protein-1 mRNA expression in obese human subjects: the role of sequence variations at the uncoupling protein-1 gene locus. J Lipid Res 1998, 39:834-844.

33. Lim JH, Ko MM, Lee HY, Go HY, Moon TW, Cha MH, Lee MS: Differential Association of Uncoupling Protein 2 Polymorphisms with Pattern Identification among Korean Stroke Patients: Diagnostic System in Traditional Korean Medicine. Evid Based Complement Alternat Med 2012, 2012:532078. Epub 2012 Aug 13.

doi:10.1186/1472-6882-12-180

Cite this article as: Lim et al:: Association of the UCP-1 single nucleotide polymorphism A-3826G with the dampness-phlegm pattern among Korean

stroke patients. BMC Complementary and Alternative Medicine 2012 12:180.

\section{Submit your next manuscript to BioMed Central and take full advantage of:}

- Convenient online submission

- Thorough peer review

- No space constraints or color figure charges

- Immediate publication on acceptance

- Inclusion in PubMed, CAS, Scopus and Google Scholar

- Research which is freely available for redistribution 